15.2

\title{
Определение трещиностойкости образцов с шевронным надрезом с использованием трехточечного изгиба
}

\author{
(C) E.E. Дерюгин ${ }^{1}$, А.А. Богданов ${ }^{2}$ \\ ${ }^{1}$ Институт фризики прочности и материаловедения СО РАН, Томск, Россия \\ ${ }^{2}$ Томский политехнический университет, Томск, Россия \\ E-mail: dee@ispms.tsc.ru
}

Поступило в Редакцию 26 июня 2021 г.

В окончательной редакции 9 июля 2021 г.

Принято к публикации 9 июля 2021 r.

\begin{abstract}
Предложен метод экспериментального определения удельной энергии разрушения материала при нагружении трехточечным изгибом образца прямоугольного сечения с шевронным надрезом. Показано, что на начальных этапах распространения трещины в зоне шевронного надреза наблюдается линейная зависимость податливости образца от длины трещины. Это позволяет вычислить удельную энергию разрушения материала без использования феноменологических уравнений, применяемых в стандартных условиях испытаний. Расчеты проведены для технического титана ВТ1-0.
\end{abstract}

Ключевые слова: трещиностойкость, трехточечный изгиб, шевронный надрез, удельная энергия разрушения, технический титан ВТ1-0.

DOI: 10.21883/PJTF.2021.20.51612.18936

Важнейшей инженерной характеристикой материала является трещиностойкость. Известны и широко применяются различные способы определения трещиностойкости (вязкости разрушения) материалов: при испытании стандартных образцов с наведенной усталостной трещиной [1], при испытаниях на ударную вязкость образцов с надрезом Шарпи [2], методом микроиндентирования [3], при нагружении изгибом [4] и др. Наиболее простым и доступным методом нагружения малоразмерных образцов является трехточечный изгиб балки прямоугольного сечения с надрезом. Стандартные условия испытаний требуют наличия в вершине надреза усталостной трещины. Нанесение трещины в образце с надрезом является достаточно трудоемкой операцией.

В настоящей работе предложен метод экспериментального определения удельной энергии разрушения при нагружении трехточечным изгибом образца прямоугольного сечения с шевронным надрезом. Для образцов такой конфигурации не требуется операции наведения на конец надреза усталостной трещины. С момента нагружения на конце шевронного надреза возникает большая концентрация напряжения, достаточная для зарождения трещины. При этом трещина сохраняет направление распространения. Геометрия шевронного надреза позволяет фиксировать и продлевать стадию стабильного распространения трещины в малоразмерных и достаточно пластичных материалах. На рис. 1, $a$ приведена схема испытаний образца с шевронным надрезом на трехточечный изгиб. На рис. $1, b$ представлено сечение балки в зоне шевронного надреза.

В основе метода лежит определение критического значения скорости высвобождения упругой энергии при распространении трещины $G$ (удельной энергии разру- шения). Необходимое условие для начала распространения подчиняется уравнению [5]:

$$
G=\frac{P^{2}}{2 a} \frac{d \eta}{d l}
$$

где $P$ - сила давления на образец (рис. $1, a), d \eta / d l-$ изменение податливости образца в процессе распространения трещины, $d l$ - малое расстояние, на которое продвигается прямолинейный фронт трещины. В двумерном варианте эта характеристика эквивалентна величине $J$-интеграла [6,7].

Максимальное значение удельной энергии разрушения $G_{c}$ является основной характеристикой трещиностойкости материала.

При экспериментальной оценке податливости образца использовался метод периодического изменения внешней нагрузки [8]. На рис. 2, a приведена диаграмма периодического нагружения сила $P$-прогиб $\lambda$ технического титана ВТ1-0, полученная на электромеханической машине INSTRON 1518 US (кривая 1). На трехточечный изгиб испытан образец в виде стержня прямоугольного сечения $a \times b=4.23 \times 5.02 \mathrm{~mm}$. Расстояние между опорами равно $l=60 \mathrm{~mm}$. Угол в вершине шевронного надреза $\alpha=60^{\circ}$. На каждом цикле определялась податливость образца по наклону прямой упругой разгрузки: $\eta=\lambda / P$. В процессе нагружения велась непрерывная фотосъемка зоны шевронного надреза камерой PENTAX K-5. По фотоизображениям была измерена длина трещины (рис. 2,b).

Из диаграммы периодического нагружения технического титана ВТ1-0 (кривая 1 на рис. 2,a) видно, что в процессе нагружения происходит заметное изменение наклона прямой упругой разгрузки, что свидетельствует 

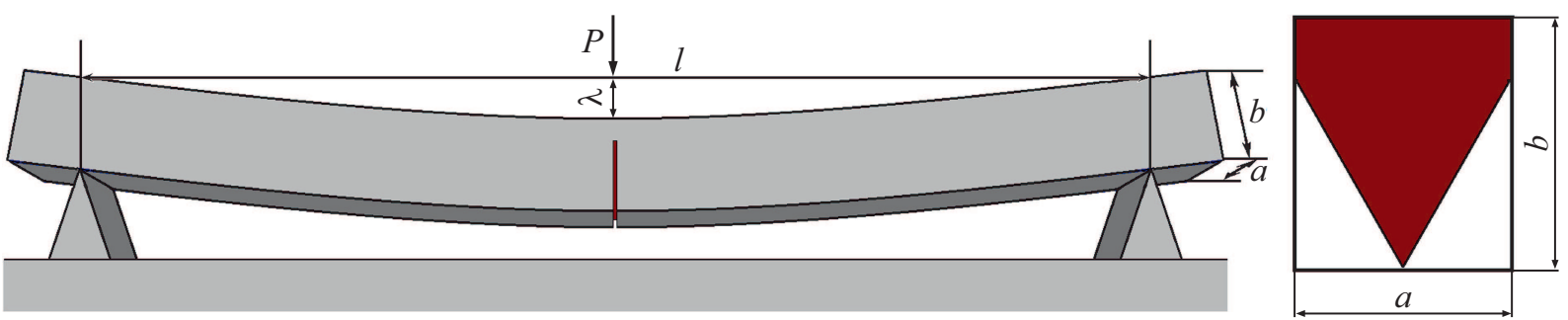

Рис. 1. Схема испытаний образца на трехточечный изгиб $(a)$ и сечение образца в зоне шевронного надреза $(b)$.

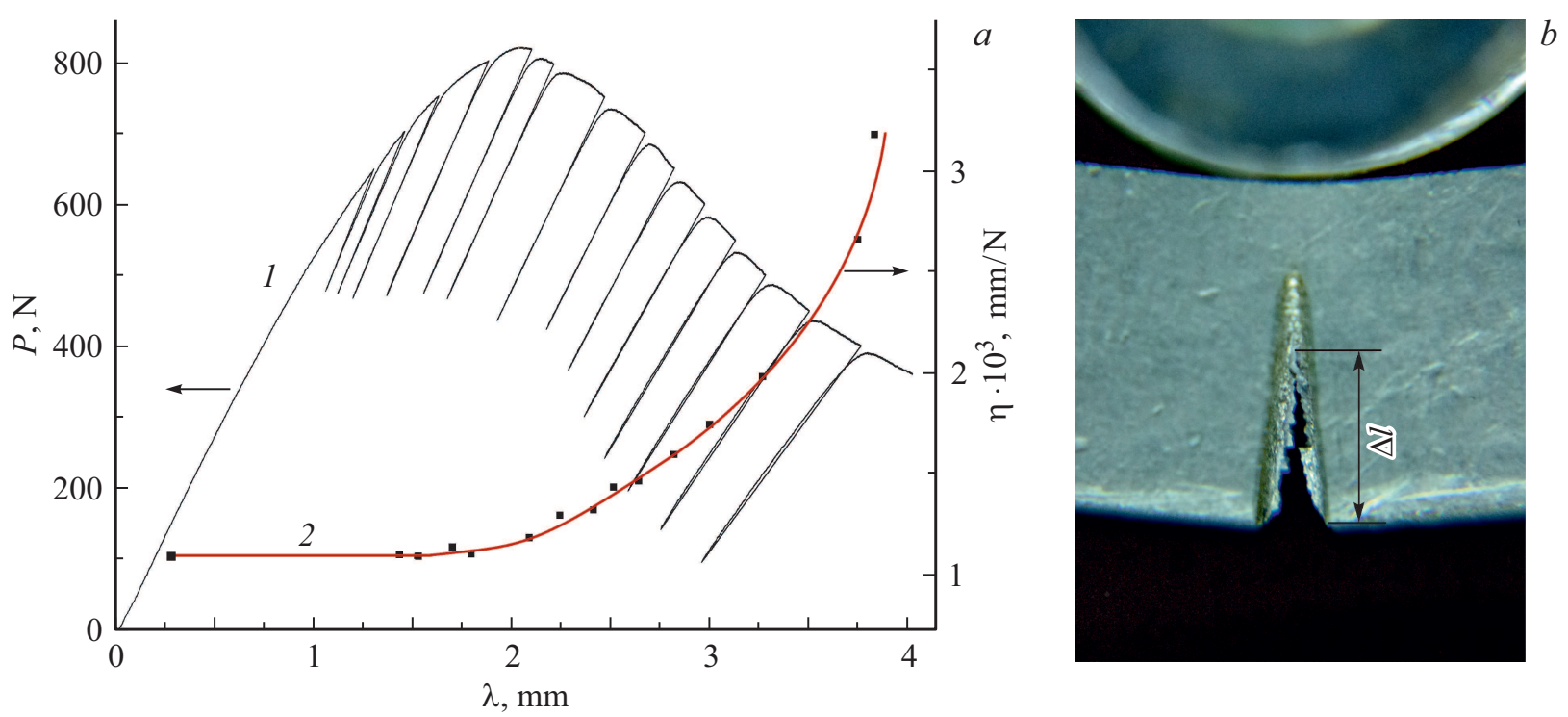

Рис. 2. $a$ - диаграмма нагружения технического титана ВТ1-0 (1) и зависимость податливости образца от величины прогиба (2). $b$ - фотоизображение трещины в зоне шевронного надреза.

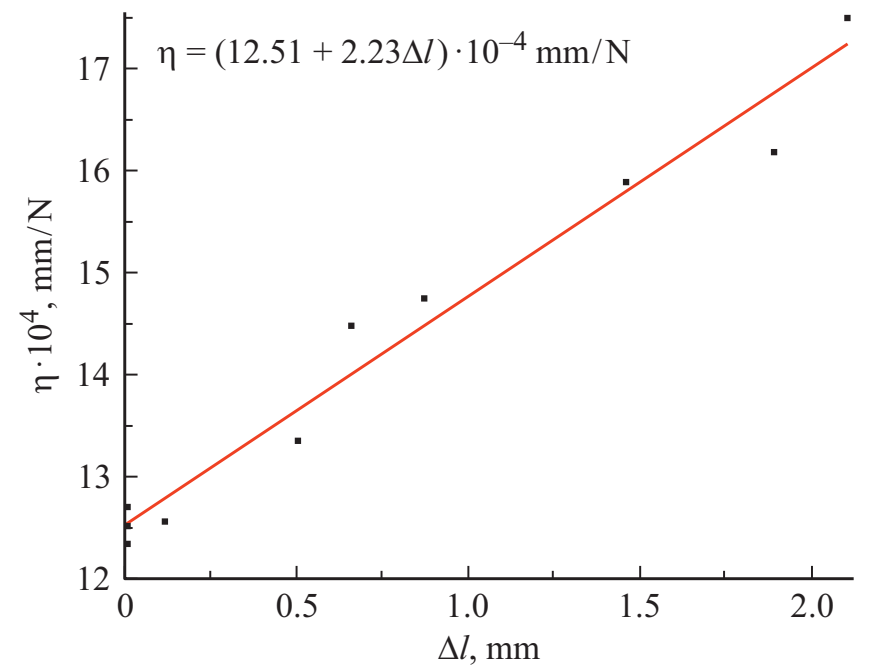

Рис. 3. Зависимость податливости образца от длины трещины.

об увеличении податливости образца и связано с распространением трещины в зоне шевронного надреза. Кри- вая 2 на рис. 2, $а$ представляет зависимость податливости образца от величины прогиба. На начальной стадии, как и следовало ожидать, податливость образца не изменяется, оставаясь на уровне $\eta=1.25 \cdot 10^{-3} \mathrm{~mm} / \mathrm{N}$. $\mathrm{C}$ момента достижения максимальной нагрузки податливость начинает плавно увеличиваться с ускорением.

Податливость образца на начальной стадии распространения трещины изменяется практически по линейному закону (рис. 3). Согласно линейной зависимости, производная податливости по длине трещины равна $d \eta / d l=2.23 \cdot 10^{-4} \mathrm{~N}^{-1}$. Подставляя это значение в уравнение (1) при $P=P_{\max }=903 \mathrm{~N}$, получим критическую величину удельной энергии разрушения $G_{c}=21.49 \mathrm{~kJ} / \mathrm{m}^{2}$. Переход от удельной энергии разрушения к коэффициенту интенсивности напряжений $K_{\mathrm{Ic}}$ осуществляется согласно известному соотношению

$$
K_{\mathrm{I} c}=\left[G_{c} E /\left(1-v^{2}\right)\right]^{1 / 2},
$$

где $E$ - модуль Юнга, $v-$ коэффициент Пуассона. Принимая для ВТ1-0 $E=112 \mathrm{GPa}$ и $v=0.3$ [9], получим критическое значение коэффициента интенсивности напряжений для технического титана 
$K_{\mathrm{Ic}}=51.43 \mathrm{MPa} \cdot \mathrm{m}^{1 / 2}$. Полученный результат близок $\mathrm{\kappa}$ справочному значению трещиностойкости технического титана ВТ1-0 [10].

Проведенные исследования показали, что предложенный метод представляет собой экспресс-метод для определения трещиностойкости малоразмерных и достаточно пластичных образцов. Материал может быть довольно пластичным, но не настолько, чтобы появление трещины было исключено. Это вытекает из принципа действия предлагаемой методики.

\section{Финансирование работы}

Работа выполнена в рамках государственного задания ИФПМ СО РАН (проект FWRW-2021).

\section{Конфликт интересов}

Авторы заявляют, что у них нет конфликта интересов.

\section{Список литературы}

[1] Standard test method for linear-elastic plane-strain fracture toughness $K_{I c}$ of metallic materials. ASTM Designation E 399-09 (West Conshohocken, PA, USA, 2009).

[2] B.N. Leis, J. Pipeline Eng., 12, 183 (2013).

[3] А.П. Крень, В.А. Рудницкий, Завод. лаб. Диагностика материалов, 74 (12), 16 (2008).

[4] H.H.N. Chen, R.K.L. Su, S.L. Fok, H.G. Zhang, Eng. Fract. Mech., 186, 143 (2017).

DOI: 10.1016/j.engfracmech.2017.09.030

[5] R.W. Hertzberg, Deformation and fracture mechanics of engineering materials, 3rd ed. (Wiley, N.Y., 1989).

[6] L.G. Malitoa, J.V. Sov, B. Gludovatz, R.O.Ritchiea, L.A. Pruitt, J. Mech. Phys. Solids, 122, 435 (2019).

DOI: $10.1016 /$ j.jmps.2018.09.022

[7] W. Brocks, Plasticity and Fracture. Solid Mechanics and its Applications book Ser. (Springer, Cham, 2018), vol. 244. DOI: 10.1007/978-3-319-62752-6

[8] T. Bolinder, Numerical simulation of ductile crack growth in residual stress field. SSM-Rapport 2014-28 (SSM, 2014). www.stralsakerhetsmundigheten.se

[9] Физические и механические свойства титана. Справочник [Электронный ресурс].

URL: https://www.mazprom.ru/spravochnik/

[10] А.Г. Илларионов, А.А. Попов. Технологические и эксплуатаиионные свойства титановых сплавов (Изд-во Урал. ун-та, Екатеринбург, 2014). https://elar.urfu.ru/ bitstream/10995/28698/1/978-5-7996-1096-8_2014.pdf 